\title{
Grain refinement and superplastic flow in a fully lamellar Ti-6Al-4V alloy
}

\section{processed by high-pressure torsion}

\author{
Wenjing Zhang ${ }^{1}$, Hua Ding ${ }^{\text {* }}$, Pedro Henrique R. Pereira ${ }^{2,3}$, \\ Yi Huang ${ }^{2,} 4^{*}$, Terence. G. Langdon ${ }^{2}$ \\ ${ }^{1}$ School of Materials Science and Engineering, Northeastern University, Shenyang 110819, China \\ ${ }^{2}$ Materials Research Group, Faculty of Engineering and the Environment, University of Southampton, \\ Southampton SO17 1BJ, U.K. \\ ${ }^{3}$ Department of Metallurgical and Materials Engineering, Universidade Federal de Minas Gerais, \\ Belo Horizonte, MG 31270-901, Brazil \\ ${ }^{4}$ Department of Design and Engineering, Faculty of Science and Technology, \\ Bournemouth University, Poole, Dorset BH12 5BB, UK
}

\begin{abstract}
A cold-rolled Ti-6Al-4V alloy was subjected to consecutive heat treatments at $1283 \mathrm{~K}$ for $1 \mathrm{~h}$ and at $823 \mathrm{~K}$ for $3 \mathrm{~h}$ in order to produce a fully lamellar microstructure. Thereafter, the material was processed by high-pressure torsion (HPT) through various numbers of turns up to a maximum of 30 . It is shown that the HPT processing leads to exceptional grain refinement with average grain sizes of $\sim 70$ and $\sim 50 \mathrm{~nm}$ after 20 and 30 turns, respectively. Tensile testing was conducted at 873 and $923 \mathrm{~K}$ with different initial strain rates using the material processed through 20 turns of HPT and this gave a maximum superplastic elongation of $820 \%$ at the relatively low temperature of $923 \mathrm{~K}$ when testing with an initial strain rate of $5.0 \times 10^{-4} \mathrm{~s}^{-1}$. The associated strain rate sensitivity for this low temperature superplasticity was estimated as $m \approx 0.5$ which is consistent with flow by grain boundary sliding.
\end{abstract}

Keywords: grain boundary sliding; grain refinement; high-pressure torsion; phase transformation; superplasticity; Ti-6Al-4V alloy.

*Corresponding author: Hua Ding (hding@263.net), Yi Huang (y.huang@soton.ac.uk) 


\section{Introduction}

The Ti-6Al-4V alloy is widely used as a superplastic material for applications in different fields including in aerospace, transportation, chemical and biomedical engineering [1-4]. However, the superplastic deformation temperature of the Ti-6Al-4V alloy is generally relatively high at $\sim 1173 \mathrm{~K}$ [5-7] and this leads to significant difficulties in many practical operations including the introduction of high tooling costs, high energy costs, low production rates and consequently a long production cycle. In order to promote energy savings and reduce the cost of tooling, several metal-working techniques have been attempted in order to refine the grain structures and thereby decrease the superplastic forming temperature $[1-4,8]$.

Processing through the use of severe plastic deformation (SPD) is generally an effective procedure for achieving exceptional grain refinement in bulk metallic materials $[9,10]$. Several SPD methods are now available but equal-channel angular pressing (ECAP) [11] and high-pressure torsion (HPT) [12] are the most widely used and the most effective techniques for producing grain refinement. In practice, and by comparison with ECAP, processing by HPT is advantageous because it produces finer grain structures $[13,14]$ and higher fractions of grain boundaries having high angles of misorientation [15]. For example, a Ti-6Al-4V alloy processed by ECAP had a refined microstructure with an average grain size of $\sim 0.3 \mu \mathrm{m}$ and when tested in tension at $973 \mathrm{~K}$ using a strain rate of $10^{-4} \mathrm{~s}^{-1}$ exhibited an elongation to failure of 474\% [4] whereas an ultrafine-grained Ti-6Al-4V alloy with a martensitic structure processed by HPT displayed a record high elongation of $815 \%$ during tensile testing at 973 $\mathrm{K}$ with a strain rate of $1.0 \times 10^{-3} \mathrm{~s}^{-1}[16]$.

The effect of the volume fraction of the lamellar structure on the HPT processing of the Ti-6Al4V alloy was investigated in several studies [16-19] and this research demonstrated that the average size of the grain structures developed during HPT processing depends upon the initial distribution of 
the lamellar structure. For example, it was shown that an HPT-processed Ti-6Al-4V alloy with an initial fully lamellar structure exhibited significant grain refinement to an average grain size of $\sim 40 \mathrm{~nm}$ [20] with a maximum elongation of $\sim 690 \%$ at $973 \mathrm{~K}$ using a strain rate of $1.0 \times 10^{-3} \mathrm{~s}^{-1}$ [17]. To date, investigations of the microstructural evolution in a fully lamellar Ti-6Al-4V alloy developed by HPTprocessing, and the consequent effect of the microstructure on the superplastic behavior, has received only limited attention. Accordingly, the present research was initiated specifically to examine the nature of grain refinement in a fully lamellar Ti-6Al-4V alloy processed by HPT and the subsequent potential for achieving superplastic flow at reasonably low temperatures.

\section{Experimental material and procedures}

A commercial Ti-6Al-4V alloy was received in the form of a cold-rolled plate with a thickness of $2.3 \mathrm{~mm}$. Disk samples having diameters of $10 \mathrm{~mm}$ and initial thicknesses of $1.15 \mathrm{~mm}$ were cut from this plate. Prior to processing by HPT, consecutive heat treatments were conducted at $1283 \mathrm{~K}$ for 1 $\mathrm{h}$ and at $823 \mathrm{~K}$ for $3 \mathrm{~h}$ followed by air cooling in order to obtain a fully lamellar structure. Hereafter, the heat-treated material is designated as the unprocessed material without any HPT processing in order to distinguish it from the HPT-processed condition. Following the heat treatment, HPT processing was performed at room temperature under quasi-constrained conditions in which there is a small outflow of material around the periphery of the disk during the processing operation [21,22]. Disks were processed through 1/4, 1/2, 1, 5, 10, 20 and 30 revolutions using a nominal applied pressure of $6.0 \mathrm{GPa}$ and a rotation speed of $1 \mathrm{rpm}$.

Following HPT processing, TEM samples were prepared using a two-step procedure. First, the HPT-processed disks were ground mechanically to a thickness of approximately $50 \mu \mathrm{m}$ and then a 3 $\mathrm{mm}$ diameter disk was punched from a position at $\sim 3 \mathrm{~mm}$ from the center of each HPT-processed disk as illustrated schematically on the left in Fig. 1. Thereafter, these small disks were subjected to twin- 
jet chemical polishing in an electrolytic solution of 5\% perchloric acid, $35 \%$ butanol and $60 \%$ methanol at a temperature of $\sim 248 \mathrm{~K}$. The microstructures of all samples were examined using a Tecnai $\mathrm{G}^{2} 20$ transmission electron microscope (TEM). The phases present before and after HPT processing were detected using an X-ray diffractometer (XRD) employing $\mathrm{Cu}$ K $\alpha$ radiation with a wavelength of $0.154 \mathrm{~nm}$ at $56 \mathrm{kV}$ and with a tube current of $182 \mathrm{~mA}$. Measurements were taken using a scanning step equal to $0.04^{\circ}$. The microstructures in the grip and gauge sections were characterized using electron backscatter diffraction (EBSD) with a step size of $0.03 \mu \mathrm{m}$ where the EBSD samples were prepared by grinding with SiC papers to 3000 grit and then using argon ion beam polishing.

Miniature tensile specimens with gauge lengths of $1.0 \mathrm{~mm}$, widths of $1.0 \mathrm{~mm}$ and thicknesses of $\sim 0.5 \mathrm{~mm}$ were cut from the disks processed through 20 turns of HPT using an off-centre configuration as shown in Fig. 1 to avoid the area of minimum torsional straining at the centre of each disk. Tensile testing was carried out using a Zwick 30KN Proline testing machine operating at a constant rate of cross-head displacement. All of the tensile specimens were held at the required testing temperature for 5 minutes prior to testing to ensure reasonably homogenous temperatures throughout the samples. The testing for superplastic deformation was performed at the relatively low temperature of $873 \mathrm{~K}$ using initial strain rates in the range from $1.0 \times 10^{-4}$ to $1.0 \times 10^{-2} \mathrm{~s}^{-1}$ and also at the higher temperature of $923 \mathrm{~K}$ with initial strain rates from $1.0 \times 10^{-4}$ to $5.0 \times 10^{-4} \mathrm{~s}^{-1}$.

\section{Experimental results}

\subsection{Microstructures of the Ti-6Al-4V alloy before and after heat treatment.}

The microstructures of the as-received material and the material after heat treatment are shown in Fig. 2(a) and (b), respectively. Before heat treatment, the microstructure of the as-received material in Fig. 2(a) shows a distorted and elongated $\alpha$-phase mixed with a small amount of $\beta$-phase. After heat treatment of $1 \mathrm{~h}$ at $1283 \mathrm{~K}$ and $3 \mathrm{~h}$ at $823 \mathrm{~K}$ in the single $\beta$-phase region, it is apparent from Fig. 
2(b) that the microstructure transforms from the initial elongated $\alpha$-phase/ $\beta$-phase mixture into a fully lamellar microstructure. The detailed morphology of the lamellar microstructure is further revealed by the TEM image in Fig. 3(a) which shows the unprocessed material prior to HPT. This microstructure consists essentially of a lamellar secondary $\alpha$-phase with a thickness of $\sim 0.7 \pm 0.2 \mu \mathrm{m}$ containing only a limited number of dislocations.

\subsection{Microstructural evolution during HPT processing}

It is well known that the torsional strain on the disks processed by HPT is inhomogeneous and the strain in the edge region is much larger than in the other regions of the disk. Therefore, microstructural evolution in the edge region occurs more rapidly until the whole disk becomes reasonably homogeneous. Figure 3 shows TEM images at positions $\sim 3 \mathrm{~mm}$ from the centres of the disk samples after (b) 1/4, (c) 1, (d) and (e) 5, (f) 10, (g) and (h) 20 and (i) and (j) 30 turns, respectively. After 1/4 turn in Fig. 3(b), it is apparent that the severe torsional straining produces a curvature in the lamellar structure with a high density of dislocations and the presence of dislocation tangles. After 1 turn in Fig. 3(c), the local shear deformation is more severe so that the lamellar structure is broken and there is an increase in the density of dislocations and dislocation tangles. When the numbers of turns increases to 5, the microstructure is further refined but remains inhomogeneous as shown in Figs 3(d) and (e). For this condition, traces of microstructural flow and the presence of shear bands are visible in some regions of the disk in Fig. 3(d) whereas some regions reveal grain refinement and the selected area electron diffraction (SAED) pattern is nearly ring-like as in Fig. 3(e). This diffraction pattern demonstrates that the misorientations between grains increase as the numbers of HPT turns also increases.

At larger numbers of turns, as after 10 turns in Fig. 3(f), the microstructure is even further refined but there remain some traces of shear deformation. Nevertheless, compared to 5 turns in Fig. 3(e), 
the SAED pattern is now more diffuse showing that the grain misorientations further increase. When the numbers of turns increases to 20 and 30 , the grains are reasonably equiaxed and essentially uniformly distributed throughout the edge regions with average sizes of $\sim 70$ and $\sim 50 \mathrm{~nm}$ after 20 and 30 turns, respectively, as shown in Figs 3(g-h) and 3(i-j). Inspection shows that the corresponding SAED patterns are approximately ring-like after 10 and 30 turns as in Figs 3(f) and (i) and it is noted especially that selected area diffraction patterns containing Debye rings after 30 turns indicate the formation of additional high-angle boundaries. From 5 to 30 turns, with the increase in numbers of turns, the SAED patterns gradually become increasingly ring-like thereby showing an increase in the grain misorientations and an evolution into increasing numbers of high-angle boundaries.

Figure 4 displays the XRD pattern for samples in the unprocessed condition (lower curve) and after HPT processing through 1/4 to 30 turns (upper curves with 30 turns in the top position). It is readily apparent that both $\alpha$-phase (hcp) and $\beta$-phase (bcc) exists in the unprocessed condition but after HPT processing there is no obvious $\beta$-phase and this confirms the dissolution of the $\beta$-phase during HPT which is consistent with earlier results [2,20] In addition, after the HPT processing there is an obvious line broadening of the diffraction peaks which corresponds to the occurrence of microstructural refinement $[23,24]$.

\subsection{High temperature mechanical properties of the HPT-processed Ti-6Al-4V alloy}

The samples processed through 20 turns were selected for mechanical testing at the relatively low temperatures of 873 and $923 \mathrm{~K}$ which contrasts with the occurrence of conventional superplastic deformation in the Ti-6Al-4V alloy at a temperature of $\sim 1173 \mathrm{~K}$. Figure 5(a) shows the tensile specimens pulled to failure at $873 \mathrm{~K}$ using different initial strain rates, $\dot{\varepsilon}$. At strain rates in the range of $10^{-3}-10^{-2} \mathrm{~s}^{-1}$ the specimens failed at relatively low elongations which were less than $400 \%$ but at even lower strain rates, from $1.0 \times 10^{-4}$ to $5.0 \times 10^{-4} \mathrm{~s}^{-1}$, the elongations to failure were high and 
consistently more than $400 \%$ where the onset of conventional superplastic flow is generally taken as an elongation of at least $400 \%$ [25]. The highest elongation at $873 \mathrm{~K}$ was $540 \%$ obtained using a strain rate of $5.0 \times 10^{-4} \mathrm{~s}^{-1}$ and this result provides a clear demonstration of the advent of low temperature superplasticity in the HPT-processed Ti-6Al-4V alloy.

Figure 5(b) shows the true stress-true strain curves of the specimens deformed at $873 \mathrm{~K}$ with different strain rates. The shapes of the curves are generally similar to those reported earlier for the Ti-6Al-4V alloy $[4,8,26,27]$. Thus, at the higher strain rates of $10^{-3}-10^{-2} \mathrm{~s}^{-1}$ the curves exhibit strain hardening whereas at the lower strain rates of $10^{-4} \mathrm{~s}^{-1}$ there are typical superplastic flow curves with relatively stable flow and low flow stresses.

The measured flow stresses at true strains of 0.3 are plotted against the initial strain rates in Fig. 5(c) for the specimens tested at $873 \mathrm{~K}$ and the average slope suggests a strain rate sensitivity, $m$, close to $\sim 0.5$ which is consistent with conventional superplasticity [28]. Although the data are limited, it appears that the value of $m$ probably increases and then decreases with increasing strain rate which is consistent with the three regions of flow which are an established feature of conventional superplastic flow [29]. It is now recognized that the superplastic flow process in superplasticity is grain boundary sliding [30] and this requires $m \approx 0.5$ [28] which applies both to conventional superplastic alloys with small grain sizes in the range of $\sim 1-5 \mu \mathrm{m}$ and to ultrafine-grained materials with grain sizes $<1 \mu \mathrm{m}$ produced using SPD techniques [31]. The present results are consistent with this approach and provide a direct explanation for the superplastic elongation of $540 \%$ achieved at $873 \mathrm{~K}$ with a strain rate of $5.0 \times 10^{-4} \mathrm{~s}^{-1}$.

Some limited results obtained at $923 \mathrm{~K}$ are shown in Fig. 5(d) where there is a maximum elongation of $820 \%$ using a strain rate of $5.0 \times 10^{-4} \mathrm{~s}^{-1}$. This result is very similar to the elongation of $815 \%$ reported earlier for a martensitic Ti-6Al-4V alloy tested at the higher temperature of $973 \mathrm{~K}$ 
using a strain rate of $1.0 \times 10^{-3} \mathrm{~s}^{-1}[16]$.

\subsection{Microstructure development in fractured tensile specimens}

To more fully reveal the superplastic flow properties of the HPT-processed Ti-6Al-4V alloy, the microstructures of the grip and gauge sections in the specimen tested to fracture at an elongation of $540 \%$ at $873 \mathrm{~K}$ with a strain rate of $5.0 \times 10^{-4} \mathrm{~s}^{-1}$ were characterized by XRD and EBSD. Figure 6 shows the XRD patterns for samples processed by HPT for 20 turns without tensile testing and in the grip section after processing through 20 turns and then pulling to failure to give the maximum measured elongation. The results show that there is no $\beta$-phase (bcc) in the HPT-processed sample after 20 turns although some very weak $\beta$ peaks are visible within the grip section after pulling to failure. These results demonstrate that a phase transformation occurs from $\alpha$-phase to $\beta$-phase during long-term exposure at the tensile deformation temperature of $873 \mathrm{~K}$.

Figure 7(a) shows the EBSD inverse pole figure (IPF) orientation map in the grip section after pulling to failure where the colour variations within the grains qualitatively represent differences in the internal misorientations as denoted in the lower unit triangle. It appears that many of the grains have crystallographic orientations of the pyramidal (0001) plane thereby suggesting that the grip section has a strong texture. Figure 7(b) shows the grain boundary image corresponding to Fig. 7(a) where the red lines represent high-angle grain boundaries (HAGBs with misorientations $>15^{\circ}$ ) and the green lines represent low-angle grain boundaries (LAGBs with misorientations between $2^{\circ}$ and $15^{\circ}$ ). This microstructure is dominated by equiaxed $\alpha$-phase grains with an average size of $\sim 0.84 \mu \mathrm{m}$ and a fraction of HAGBs of $\sim 84 \%$. A very small volume fraction of the $\beta$-phase, corresponding to $\mathrm{V}_{\beta} \approx$ $0.51 \%$, was detected in the grip section displayed by the blue regions in Fig. 7(b).

Similar images are shown in Figs 7(c) and (d) for the EBSD IPF map and the corresponding grain boundary image within the gauge section. Compared to the microstructure in the grip section shown 
in Fig. 7(a), the gauge section exhibits nearly random crystallographic orientations which are a direct consequence of the grain rotation occurring during the tensile deformation. Furthermore, the equiaxed structure in the gauge section has now increased with a fraction of HAGBs of $~ 95 \%$ but only a minor change in grain size to $\sim 0.88 \mu \mathrm{m}$. The volume fraction of the $\beta$-phase in the gauge section is now $\mathrm{V}_{\beta} \approx 1.97 \%$ which is higher than in the grip section where this difference is probably due to the tensile deformation-induced $\beta$-phase transformation [32].

\section{Discussion}

\subsection{Grain refinement during HPT processing}

These results demonstrate that processing by HPT produces a very substantial grain refinement in the Al-6Al-4V alloy. There are several factors influencing this grain refinement such as the applied pressure, the number of turns in torsional straining, the friction factor between the disk and the anvils and the imposed temperature of processing. There is also the additional increase in temperature that occurs during processing as a direct consequence of the HPT although experiments on a number of pure metals, including $\mathrm{Ti}$, show that this temperature rise is minor by comparison with the melting temperature of the processed metal [33]. The effect of the numbers of turns in HPT was investigated in several reports $[18,19,34]$ and it is recognized that the microstructure becomes finer and more homogeneous with increasing straining. The grain sizes achieved in the present investigation were $\sim 70$ and $\sim 50 \mathrm{~nm}$ after 20 and 30 turns, respectively, and these values are generally smaller than those reported using other SPD methods with the Ti-6Al-4V alloy: for example, there are reports of grain sizes of $\sim 350 \mathrm{~nm}[35], \sim 300 \mathrm{~nm}[3,4]$ and $~ 170 \mathrm{~nm}[36]$ after ECAP processing, $300 \mathrm{~nm}$ [37] and $\sim 135 \mathrm{~nm}$ [38] after processing by multidirectional forging (MF) and 70-210 nm after using friction stir processing (FSP) [39]. It should be noted that an earlier report on the processing of Ti-6Al-4V by HPT gave grain sizes of $\sim 30$ and $\sim 40 \mathrm{~nm}$ after 10 turns for initial martensitic and lamellar structures, 
respectively [16]. The smaller grain sizes achieved using HPT processing confirm the advantage of using this procedure.

For dual phase materials, the volume fraction of the lamellar structure is also an important factor influencing the grain refinement. Thus, the Ti-6Al-4V alloy is a typical dual phase alloy containing both $\alpha$-phase and $\beta$-phase boundaries although heat treatments may be conducted to obtain different volume fractions of the lamellar structure [16]. Most recently, a report on the influence of the volume fraction of the lamellar structure on grain refinement showed that the refinement was more significant when the volume fraction of the lamellar structure was increased [19]. Thus, for 30\% lamellar structure the grain size was $\sim 115 \pm 30 \mathrm{~nm}$ after 20 turns but when the fraction of lamellar structure was increased to $75 \%$ the average grain size decreased to $\sim 75 \pm 15 \mathrm{~nm}$ [19]. This latter value is larger than the grain sizes of $\sim 70$ and $\sim 50 \mathrm{~nm}$ obtained after 20 and 30 turns in the fully lamellar structure in the present work.

\subsection{Low temperature superplasticity in HPT-processed Ti-6Al-4V}

The basic requirements for superplastic flow are now well established. Specifically, superplasticity requires a grain size smaller than $\sim 10 \mu \mathrm{m}$ and a testing temperature above $\sim 0.5 T_{\mathrm{m}}$ where $T_{\mathrm{m}}$ is the absolute melting temperature of the material [40]. It is generally difficult to retain a very small grain size at an elevated temperature but this limitation may be overcome through the use of two-phase alloys where grain growth is limited by the presence of different phases or by using a fine dispersion of a second phase to act as a grain refiner. In the Ti-6Al-4V alloy this role is undertaken by the presence of both the $\alpha$ and $\beta$ phases. In the present work the microstructure of the sample processed by HPT through 20 turns, where the as-processed grain size was $\sim 70 \mathrm{~nm}$, exhibited very good thermal stability during tensile testing at $873 \mathrm{~K}$ when using a strain rate of $5.0 \times 10^{-4} \mathrm{~s}^{-1}$. Thus, the average grain sizes after failure at an elongation of $540 \%$ were only $\sim 0.84$ and $\sim 0.88 \mathrm{~nm}$ in 
the grip and gauge sections, respectively, and these values demonstrate there is only minor grain growth during the relatively long-term tensile testing. Furthermore, the high number fraction of $95 \%$ of HAGBs within the gauge section at $873 \mathrm{~K}$ is consistent with the occurrence of flow by grain boundary sliding and with the well-established demonstration, based on early experiments with bicrystals, that no sliding occurs at boundary misorientations $<5^{\circ}$ and HAGBs are a necessary prerequisite for the occurrence of extensive grain boundary sliding [41]. It is also consistent with earlier results showing the influence of the presence of HAGBs in the superplastic properties of an ultrafine-grained Al-MgSc alloy [42].

This high volume fraction of HAGBs in the highly superplastic specimen, combined with the random crystallographic orientations formed within the gauge section during tensile testing which are favourable for superplastic flow [43], is consistent also with the occurrence of low temperature superplasticity as reported in the first mechanical testing of an ultrafine-grained metallic alloy processed using HPT [44]. In the present investigation, the elongations of $540 \%$ at $873 \mathrm{~K}$ and $820 \%$ at $923 \mathrm{~K}$ provide a direct demonstration of the occurrence of excellent low temperature superplasticity in the Ti-6Al-4V alloy.

\section{Summary and conclusions}

1. A cold-rolled Ti-6Al-4V alloy was subjected to appropriate heat treatments to produce a fully lamellar microstructure and then processed by HPT at room temperature through different numbers of turns. Processing by HPT produced significant grain refinement with grain sizes of $\sim 70$ and $\sim 50 \mathrm{~nm}$, respectively, after 20 and 30 turns.

2. Tensile testing of the HPT-processed alloy gave excellent low temperature superplasticity at 873 and $923 \mathrm{~K}$ using an initial strain rate of $5.0 \times 10^{-4} \mathrm{~s}^{-1}$ with maximum elongations of $540 \%$ and $820 \%$ at these two temperatures, respectively. 
3. A measured strain rate sensitivity of $m \approx 0.5$ and the presence of an equiaxed microstructure within the gauge section for tensile fractured specimens were consistent with the occurrence of grain boundary sliding as the flow process.

\section{Acknowledgements}

This investigation was supported in part by the National Natural Science Foundation of China under Grant No. 51334006 (WZ, HD) and in part by the European Research Council under Grant Agreement No. 267464-SPDMETALS (PHRP, YH, TGL).

\section{Data availability}

The raw/processed data required to reproduce these findings cannot be shared at this time as the data also forms part of an ongoing study. 


\section{References}

[1] J.S. Kim, Y.W. Chang, S.L. Chong, Quantitative analysis on boundary sliding and its accommodation mode during superplastic deformation of two-phase Ti-6Al-4V alloy, Metall. Mater. Trans. A 29 (1998) 217-226.

[2] A.V. Sergueeva, V.V. Stolyarov, R.Z. Valiev, A.K. Mukherjee, Enhanced superplasticity in a Ti6Al-4V alloy processed by severe plastic deformation, Scr. Mater. 43 (2000) 819-824.

[3] Y.G. Ko, W.G. Kim, S.L. Chong, H.S. Dong, Microstructural influence on low-temperature superplasticity of ultrafine-grained Ti-6Al-4V alloy, Mater. Sci. Eng. A 410 (2005) 156-159.

[4] Y.G. Ko, C.S. Lee, D.H. Shin, S.L. Semiatin, Low-temperature superplasticity of ultra-finegrained Ti-6Al-4V processed by equal-channel angular pressing, Metall. Mater. Trans. A 37A (2006) 381-391.

[5] R.Y. Lutfullin, O.A. Kaibyshev, R.V. Safiullin, O.R. Valiakhmetov, M.H. Mukhametrahimov, Superplasticity and solid state bonding of titanium alloys, Acta Metall Sinica, 13 (2000) 561-566.

[6] G.A. Salishchev, R.M. Galeyev, O.R. Valiakhmetov, R.V. Safiullin, R.Y. Lutfullin, O.N. Senkov, F.H. Froes, O.A. Kaibyshev, Development of Ti-6Al-4V sheet with low temperature superplastic properties, J. Mater. Process. Tech. 116 (2001) 265-268.

[7] S.V. Zherebtsov, E.A. Kudryavtsev, G.A. Salishchev, B.B. Straumal, S.L. Semiatin, Microstructure evolution and mechanical behavior of ultrafine Ti-6Al-4V during low-temperature superplastic deformation, Acta Mater. 121 (2016) 152-163.

[8] A.V. Sergueeva, V.V. Stolyarov, R.Z. Valiev, A.K. Mukherjee, Superplastic behavior of ultrafinegrained Ti-6A1-4V alloys, Mater. Sci. Eng. A 323 (2002) 318-325.

[9] R.Z. Valiev, R.K. Islamgaliev, I.V. Alexandrov, Bulk nanostructured materials from severe plastic deformation, Prog. Mater. Sci. 45 (2000) 103-189. 
[10]T.G. Langdon, Twenty-five years of ultrafine-grained materials: achieving exceptional properties through grain refinement, Acta Mater. 61 (2013) 7035-7059.

[11]R.Z. Valiev, T.G. Langdon, Principles of equal-channel angular pressing as a processing tool for grain refinement, Prog. Mater. Sci. 51 (2006) 881-981.

[12] A.P. Zhilyaev, T.G. Langdon, Using high-pressure torsion for metal processing: fundamentals and applications, Prog. Mater. Sci. 53 (2008) 893-979.

[13] A.P. Zhilyaev, B.K. Kim, G.V. Nurislamova, M.D. Baró, J.A. Szpunar, T.G. Langdon, Orientation imaging microscopy of ultrafine-grained nickel, Scr. Mater. 46 (2002) 575-580.

[14]A.P. Zhilyaev, G.V. Nurislamova, B.K. Kim, M.D. Baró, J.A. Szpunar, T.G. Langdon, Experimental parameters influencing grain refinement and microstructural evolution during highpressure torsion, Acta Mater. 51 (2003) 753-765.

[15] J. Wongsa-Ngam, M. Kawasaki, T.G. Langdon, A comparison of microstructures and mechanical properties in a $\mathrm{Cu}-\mathrm{Zr}$ alloy processed using different SPD techniques, J. Mater. Sci. 48 (2013) $4653-4660$.

[16]H. Shahmir, F. Naghdi, P.H.R. Pereira, Y. Huang, T.G. Langdon, Factors influencing superplasticity in the Ti-6Al-4V alloy processed by high-pressure torsion, Mater. Sci. Eng. A 718 (2018) 198-206.

[17] Y.C. Wang, T.G. Langdon, Influence of phase volume fractions on the processing of a Ti-6Al-4V alloy by high-pressure torsion, Mater. Sci. Eng. A 559 (2013) 861-867.

[18] Y.C. Wang, T.G. Langdon, Effect of heat treatment on microstructure and microhardness evolution in a Ti-6Al-4V alloy processed by high-pressure torsion, J. Mater. Sci. 48 (2013) 4646-4652.

[19] J. Fu, H. Ding, Y. Huang, W.J. Zhang, T.G. Langdon, Influence of phase volume fraction on the grain refining of a Ti-6Al-4V alloy by high-pressure torsion, J. Mater. Res. Tech. 4 (2015), 2-7. 
[20]H. Shahmir, T.G. Langdon, Using heat treatments, high-pressure torsion and post-deformation annealing to optimize the properties of Ti-6Al-4V alloys, Acta Mater. 141 (2017) 419-416.

[21]R.B. Figueiredo, P.R. Cetlin, T.G. Langdon, Using finite element modeling to examine the flow processes in quasi-constrained high-pressure torsion, Mater. Sci. Eng. A 528 (2011) 8198-8204.

[22] R.B. Figueiredo, P.H.R. Pereira, M.T.P. Aguilar, P.R. Cetlin, T.G. Langdon, Using finite element modelling to examine the temperature distribution in quasi-constrained high-pressure torsion, Acta Mater. 60 (2012) 3190-3198.

[23]Z.Q. Zhang, L.M. Dong, Y. Yang, S.X. Guan, Y.Y. Liu, R. Yang, Microstructure refinement of a dual phase titanium alloy by severe room temperature compression, Trans. Nonferrous Metall. Soc. China 22 (2012) 2604-2608.

[24]C.T. Wang, A.G. Fox, T.G. Langdon, Microstructural evolution in ultrafine-grained titanium processed by high-pressure torsion under different pressures, J. Mater. Sci. 49 (2014) 6558-6564.

[25] T.G. Langdon, Seventy-five years of superplasticity: historic developments and new opportunities, J. Mater. Sci. 44 (2009) 5998-6010.

[26]L.H. Wu, B.L. Xiao, D.R. Ni, Z.Y. Ma, X.H. Li, M.J. Fu, Y.S. Zeng, Achieving superior superplasticity from lamellar microstructure of a nugget in a friction-stir-welded Ti-6Al-4V joint, Scr. Mater. 98 (2015) 44-47.

[27]L.H. Wu, P. Xue, B.L. Xiao, Z.Y. Ma, Achieving superior low-temperature superplasticity for lamellar microstructure in nugget of a friction stir welded Ti-6Al-4V joint, Scr. Mater. 122 (2016) 26-30.

[28]T.G. Langdon, A unified approach to grain boundary sliding in creep and superplasticity, Acta Metall. Mater. 42 (1994) 2437-2443. 
[29] H. Ishikawa, F.A. Mohamed, T.G. Langdon, The influence of strain rate on ductility in the superplastic Zn-22\% Al eutectoid, Phil. Mag. 32 (1975) 1269-1271.

[30]T.G. Langdon, An evaluation of the strain contributed by grain boundary sliding in superplasticity, Mater. Sci. Eng. A 174 (1994) 225-230.

[31]M. Kawasaki, T.G. Langdon, Review: achieving superplastic properties in ultrafine-grained materials at high temperatures, J. Mater. Sci. 51 (2016) 19-32.

[32]H. Matsumoto, K. Yoshida, S.H. Lee, Y. Ono, A. Chiba, Ti-6Al-4V alloy with an ultrafine-grained microstructure exhibiting low-temperature-high-strain-rate superplasticity, Mater. Lett. 98 (2013) 209-212.

[33] K. Edalati, Y. Hashiguchi, P.H.R. Pereira, Z. Horita, T.G. Langdon, Effect of temperature rise on microstructural evolution during high-pressure torsion, Mater. Sci. Eng. A 714 (2018) 167-171.

[34] J. Fu, H. Ding, Y. Huang, P.H.R. Pereira, W.J. Zhang, T.G. Langdon, Grain refining of a Ti-6Al4V alloy by high-pressure torsion and low temperature superplasticity, Lett. Mater. 5 (2015) 281286.

[35]G.G. Yapici, I. Karaman, Z.P. Luo, Mechanical twinning and texture evolution in severely deformed Ti-6Al-4V at high temperatures, Acta Mater. 54 (2006) 3755-3771.

[36]L.R. Saitova, H.W. Höppel, M. Göken, Fatigue behavior of ultrafine-grained Ti-6Al-4V 'ELI' alloy for medical applications, Mater. Sci. Eng. A 503 (2009) 145-147.

[37]G.A. Salishchev, O.R. Valiakhmetov, V. Valitov, S.K. Mukhtarov, Submicrocrystalline and nanocrystalline structure formation in materials and search for outstanding superplastic properties, Mater. Sci. Forum 170-172 (1994) 121-130. 
[38]G.A. Salishchev, E.A. Kudryavtsev, S.V. Zherebtsov, S.L. Semiatin, Low temperature superplasticity of Ti-6Al-4V processed by warm multidirectional forging, Mater. Sci. Forum 735 (2012) 253-258.

[39] Y. Sungook, R. Ueji, H. Fujii, Effect of initial microstructure on Ti-6Al-4V joint by friction stir welding, Mater. Des. 88 (2015) 1269-1276.

[40]T.G. Langdon, The mechanical properties of superplastic materials, Metall. Trans. A 13A (1982) $681-701$.

[41]F. Weinberg, Trans. AIME, Grain boundary shear in aluminum, 212 (1958) 808-817.;

[42]F.C. Liu, Z.Y. Ma, F.C. Zhang, High strain rate superplasticity in a micro-grained Al-Mg-Sc alloy with predominant high angle grain boundaries, J. Mater. Sci. Technol. 28 (2012) 1025-1030.

[43]Q. Yang, A.H. Feng, B.L. Xiao, Z.Y. Ma, Influence of texture on superplastic behavior of friction stir processed ZK60 magnesium alloy, Mater. Sci. Eng. A 556 (2012) 671-677

[44]R.Z. Valiev, O.A. Kaibyshev, R.I. Kuznetsov, R.Sh. Musalimov, N.K. Tsenev, Low-temperature superplasticity of metallic materials, Dokl. Akad. Nauk SSSR 301 (1988) 864-866. 


\section{Figure captions}

Fig. 1 Schematic illustration of HPT disk showing locations of the TEM sample and the tensile testing specimen: all dimensions in $\mathrm{mm}$.

Fig.2 Microstructures of the alloy (a) before heat treatment and (b) after heat treatment for $1283 \mathrm{~K} / 1 \mathrm{~h}+823 \mathrm{~K} / 3 \mathrm{~h}$ and air cooling.

Fig. 3 TEM images before and after processing by HPT for different numbers of turns: (a) unprocessed, (b) 1/4 turn, (c) 1 turn, (d) and (e) 5 turns, (f) 10 turns, (g) and (h) 20 turns, (i) and (j) 30 turns.

Fig. 4 X-ray patterns of the Ti-6Al-4V alloy before and after processing by HPT through different numbers of turns.

Fig. 5 (a) Tensile specimens pulled to failure at $873 \mathrm{~K}$ using different initial strain rates, (b) true stress-true strain curves at $873 \mathrm{~K}$, (c) variation of flow stress with initial strain rate at $873 \mathrm{~K}$ and (d) tensile specimens pulled to failure at $923 \mathrm{~K}$ at two different strain rates.

Fig.6 X-ray patterns of the sample processed by HPT for 20 turns without tensile testing and in the grip section after tensile testing to failure.

Fig.7 EBSD inverse pole figure maps boundary maps of grip (upper) and gauge (lower) sections: (a) IPF map and (b) grain boundary map in grip section, (c) IPF map and (d) grain boundary map in gauge section; in (b) and (d) the green lines are LAGBs, the red lines are HAGBs and the blue regions are the $\beta$-phase. 


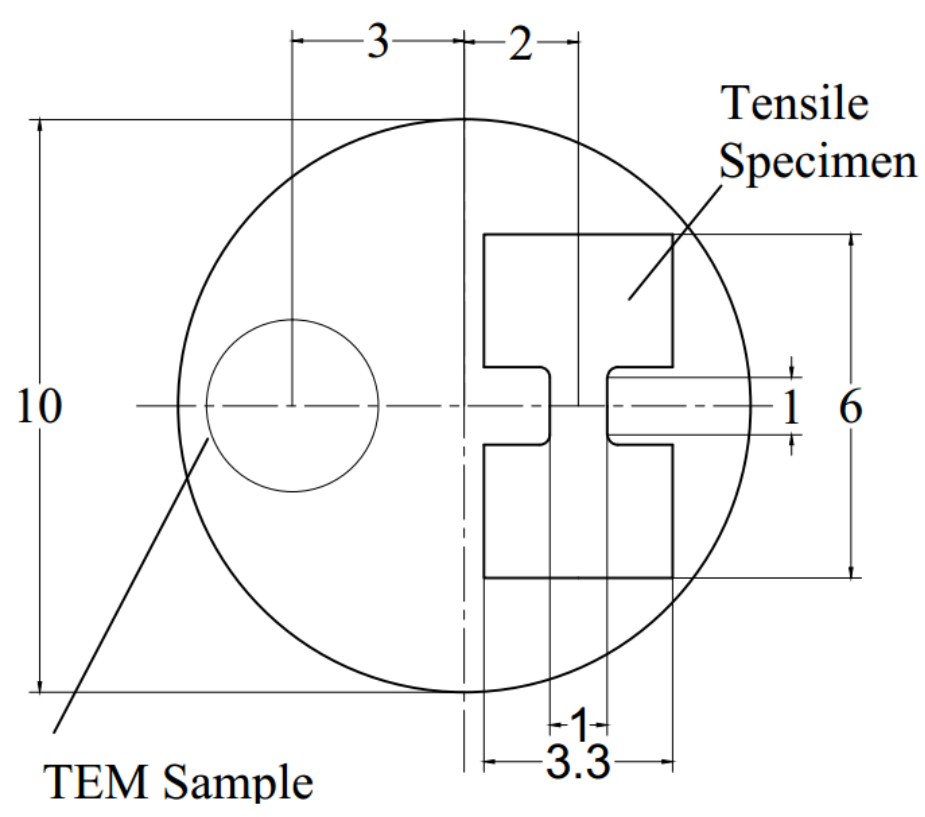

Fig. 1 Schematic illustration of HPT disk showing locations of the TEM sample and the tensile testing specimen: all dimensions in $\mathrm{mm}$.

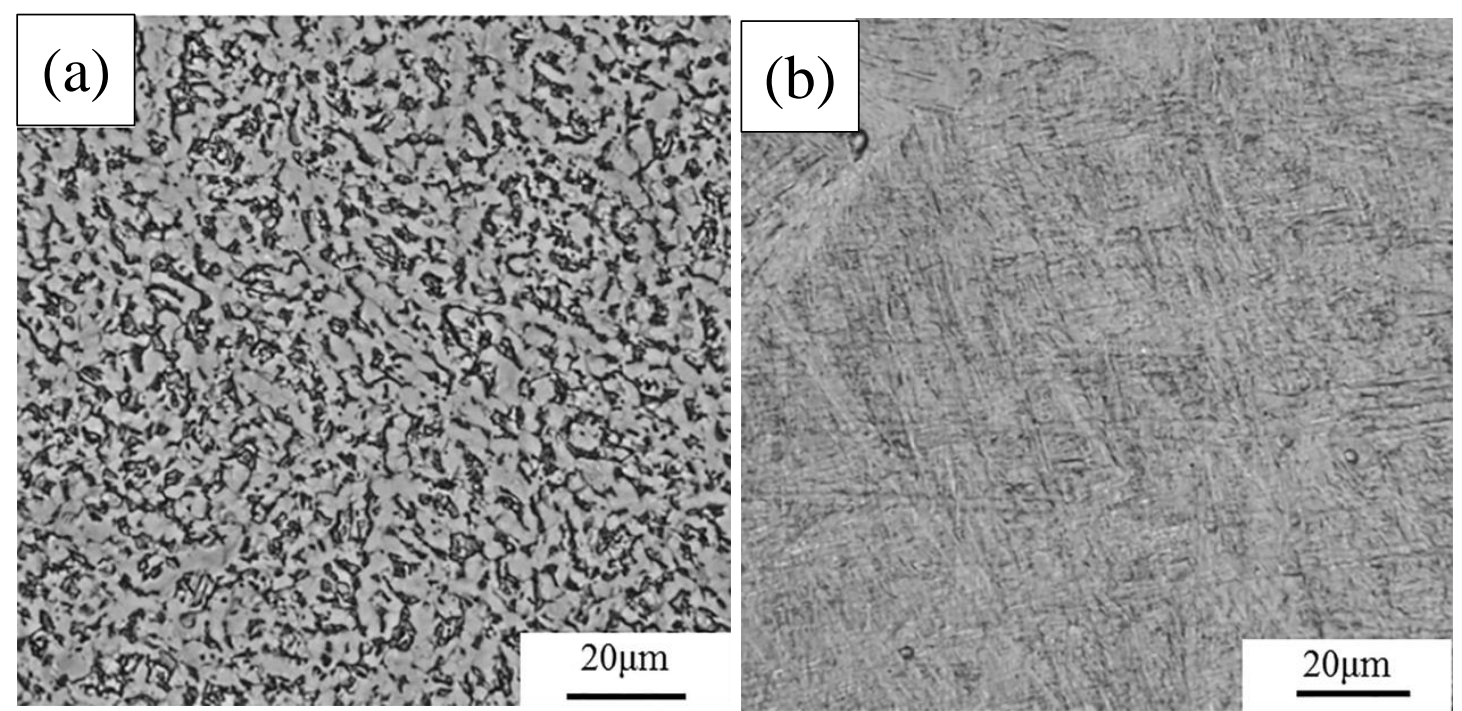

Fig. 2 Microstructures of the alloy (a) before heat treatment and (b) after heat treatment for 1283 $\mathrm{K} / \mathrm{h}+823 \mathrm{~K} / 3 \mathrm{~h}$ and air cooling. 


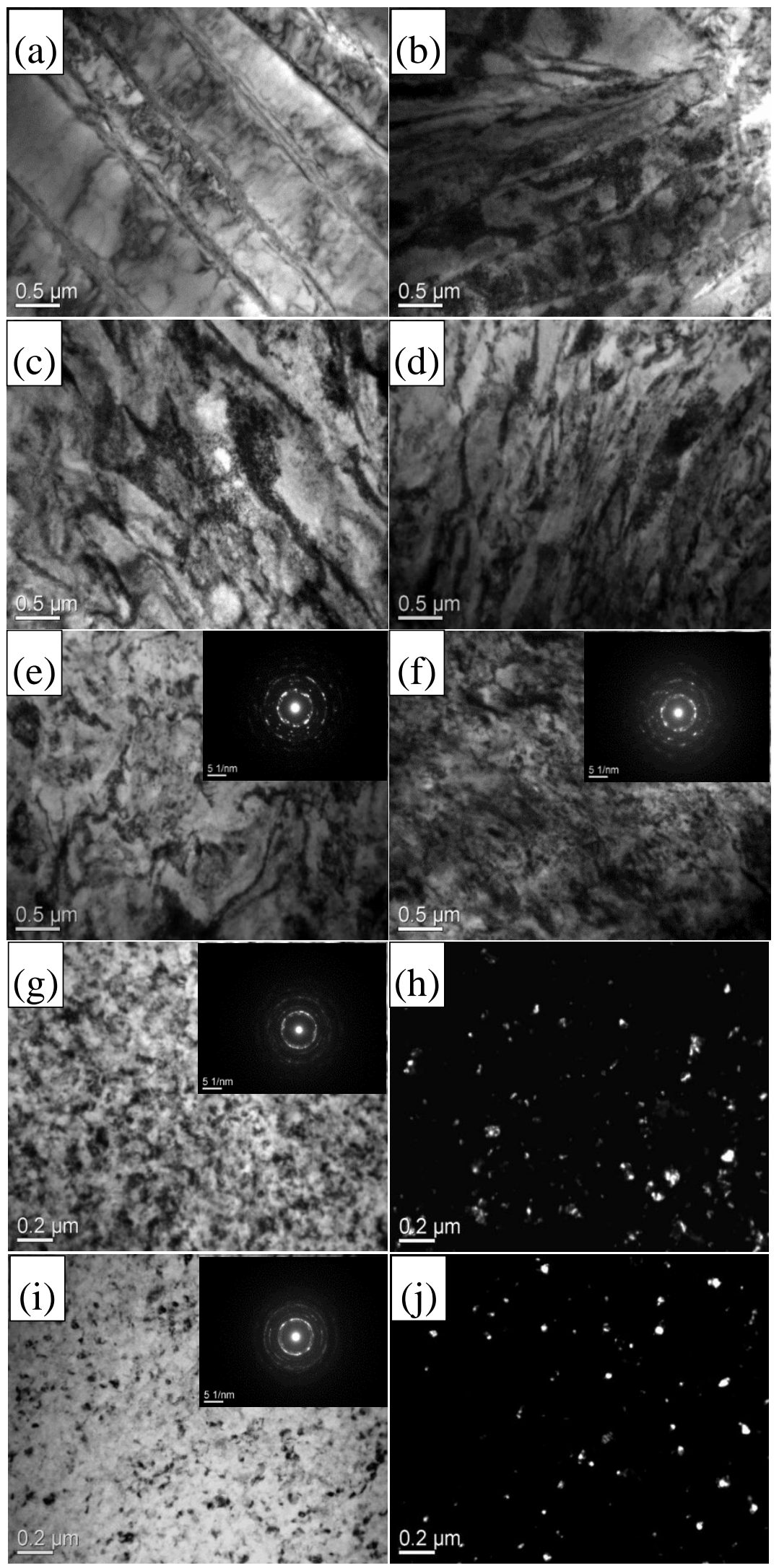

Fig. 3 TEM images before and after processing by HPT for different numbers of turns: (a) unprocessed, (b) 1/4 turn, (c) 1 turn, (d) and (e) 5 turns, (f) 10 turns, (g) and (h) 20 turns, (i) and (j) 30 turns. 


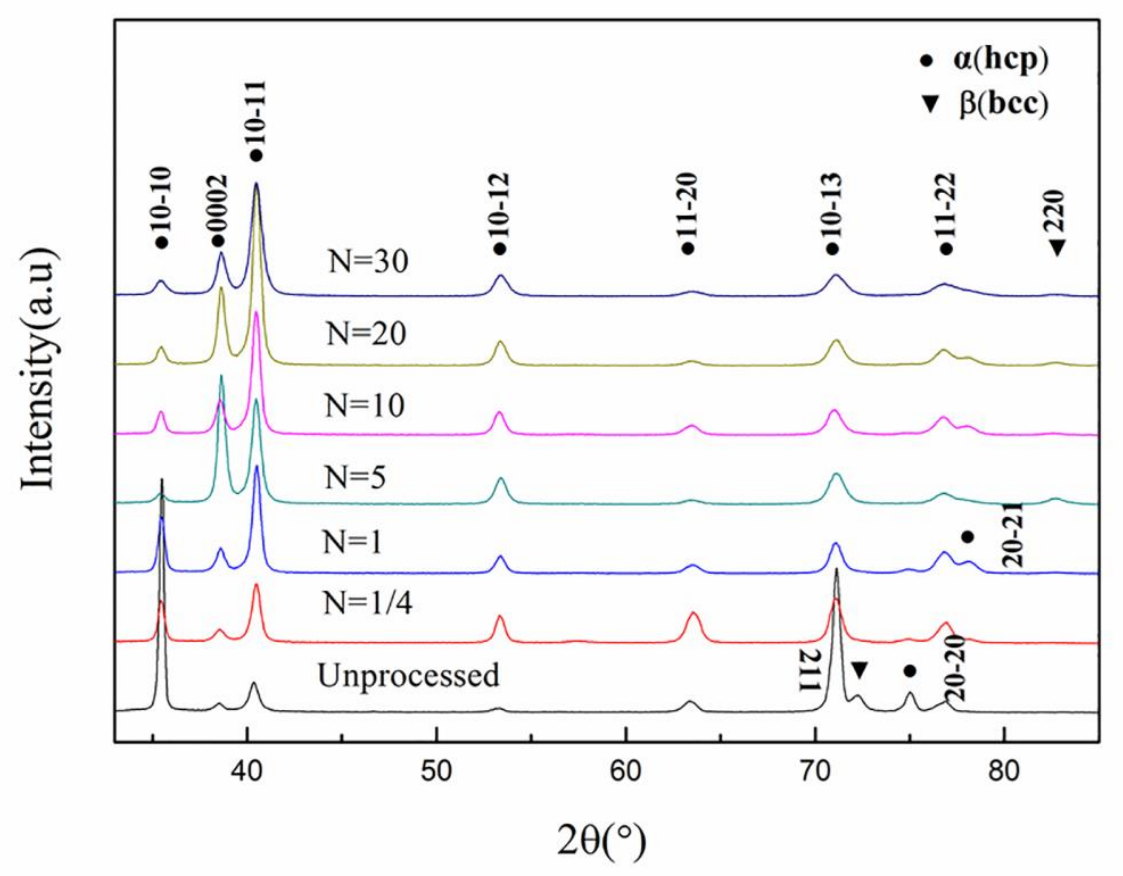

Fig. 4 X-ray patterns of the Ti-6Al-4V alloy before and after processing by HPT through different numbers of turns. 
(a)

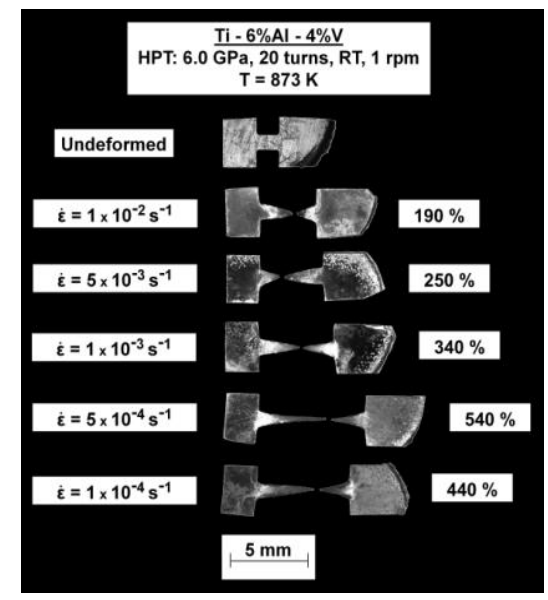

(c)

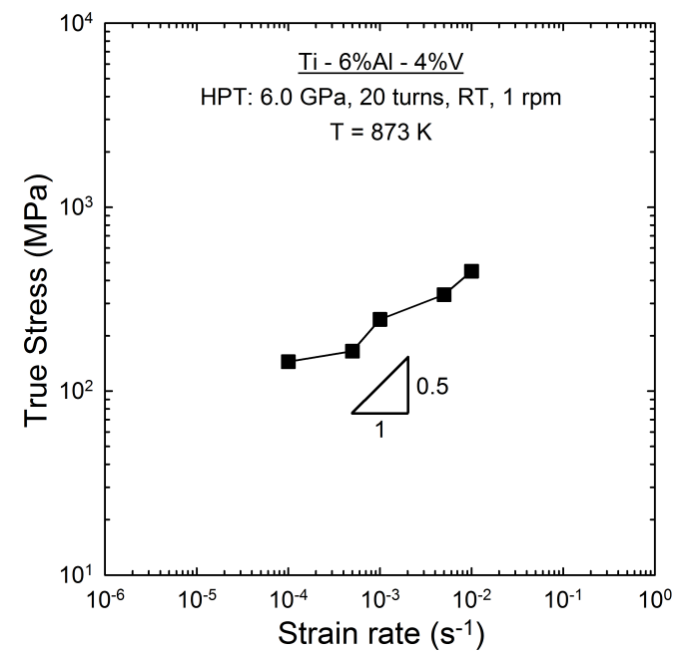

(b)

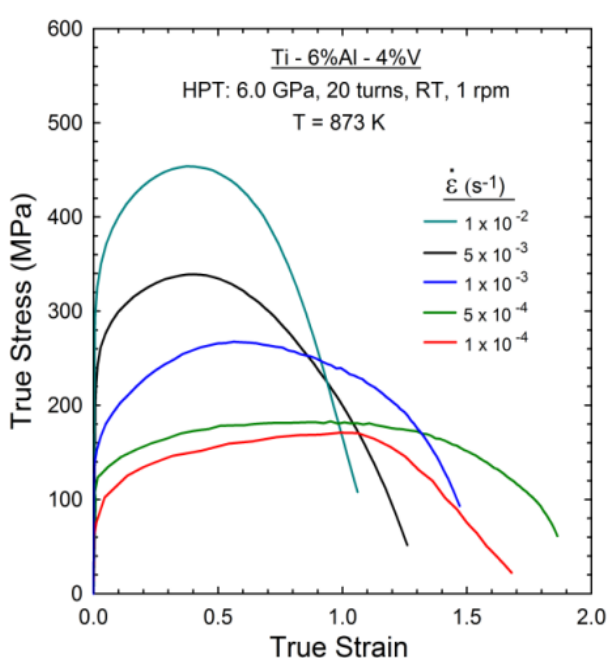

(d)

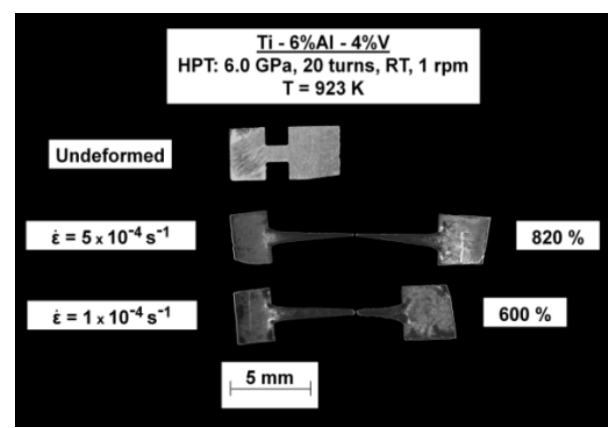

Fig. 5 (a) Tensile specimens pulled to failure at $873 \mathrm{~K}$ using different initial strain rates, (b) true stress-true strain curves at $873 \mathrm{~K}$, (c) variation of flow stress with initial strain rate at $873 \mathrm{~K}$ and (d) tensile specimens pulled to failure at $923 \mathrm{~K}$ at two different strain rates. 


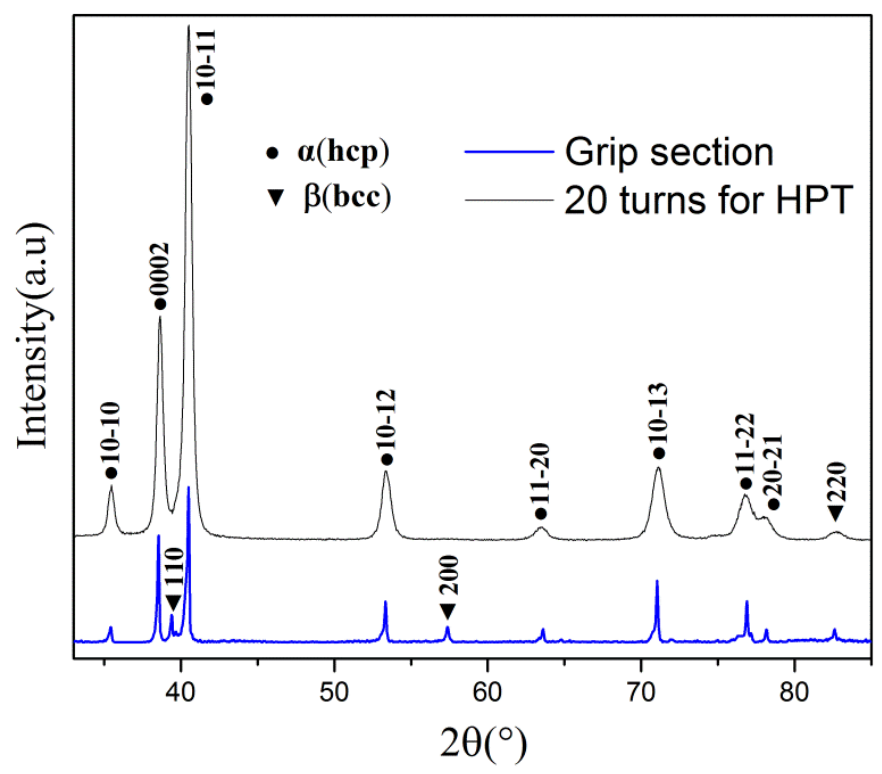

Fig. 6 X-ray patterns of the sample processed by HPT for 20 turns without tensile testing and in the grip section after tensile testing to failure.

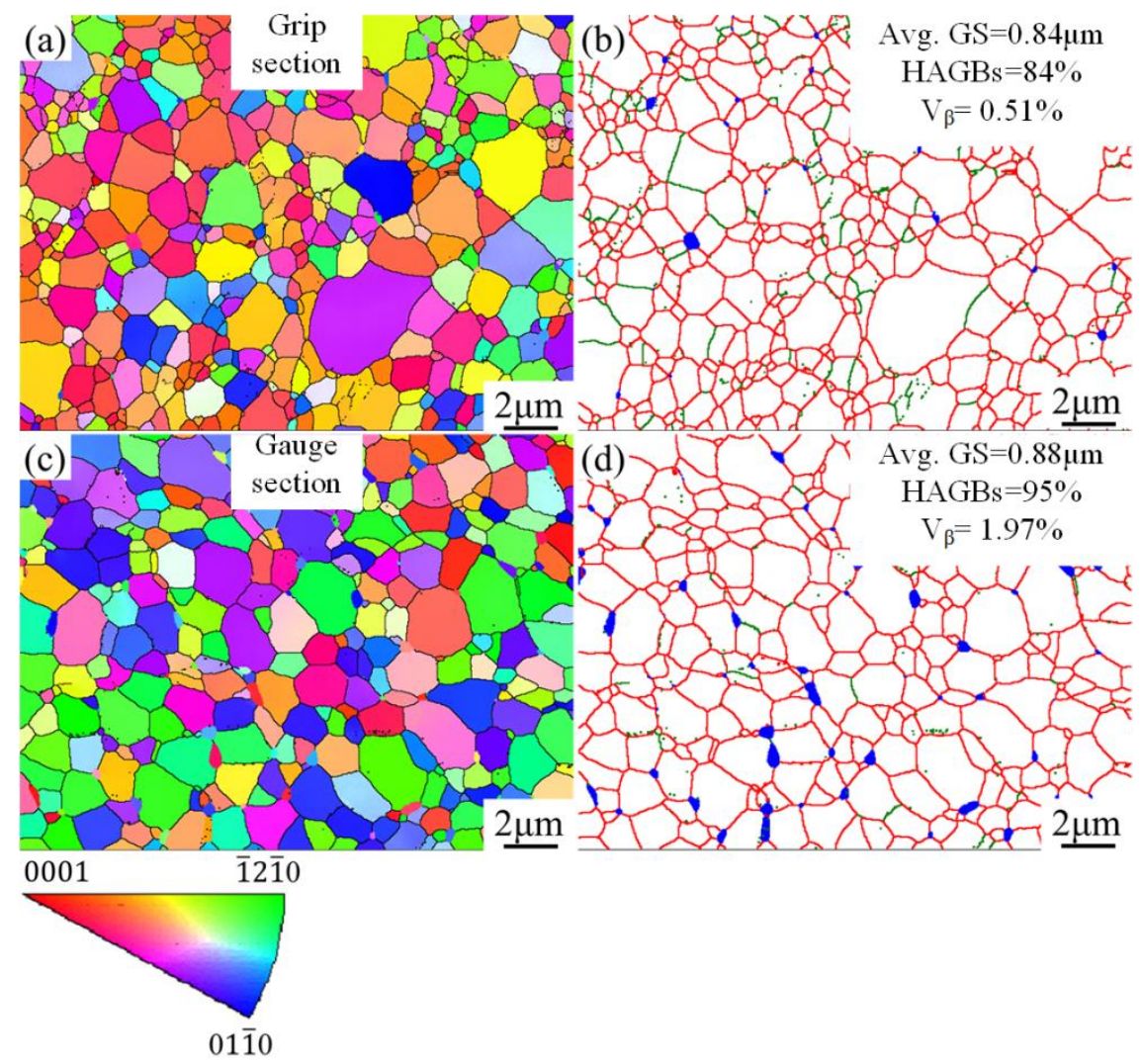

Fig. 7 EBSD inverse pole figure maps boundary maps of grip (upper) and gauge (lower) sections: (a) IPF map and (b) grain boundary map in grip section, (c) IPF map and (d) grain boundary map in gauge section; in (b) and (d) the green lines are LAGBs, the red lines are HAGBs and the blue regions are the $\beta$-phase. 